\title{
Corpus callosum and epilepsies
}

\author{
Gerhard Bauer ${ }^{1}$, Elżbieta Płonka-Półtorak ${ }^{2}$, Richard Bauer ${ }^{3}$, Iris Unterberger ${ }^{1}$, Giorgi Kuchukhidze ${ }^{4}$ \\ 1 Department of Neurology, Medical University Innsbruck, Austria \\ ${ }^{2}$ Antiepileptic Outpatient Clinic, Provincial Hospital, Rzeszow, Poland \\ ${ }^{3}$ Landeskrankenhaus Feldkirch, Department of Neurosurgery, \\ Feldkirch, Austria \\ ${ }^{4}$ Department of Neurology, Christian Doppler Klinik, \\ Paracelsus Medical University, Salzburg, Austria
}

Correspondence

Prof. Dr. Gerhard Bauer, Department of Neurology, Medical University A-6020 Innsbruck, Anichstr. 35, Austria e-mail gerhard.bauer@i-med.ac.at

\section{SUMMARY}

Introduction. Corpus callosum (CC) is the largest forebrain commissure. Structural anomalies and accompanying clinical symptoms are not in the focus of neurologists, epileptologists or neurosurgeons.

Aim and method. Anatomy, embryological development, normal functions, structural abnormalities, additional malformations, clinical symptoms and seizure disorders with CC anomalies are reviewed from the literature. Review. The detection of callosal anomalies increased rapidly with widespread use of brain imaging methods. Agenesis or dysgenesis of corpus callosum (AgCC) might be considered an accidental finding. Epileptic seizures occur in up to $89 \%$ of patients with AgCC. The causal relationship correctly is questioned. However, additional causative malformations of midline and/or telencephalic structures can be demonstrated in most seizure patients. The interruption of bilateral spread of seizure activities acts as the concept for callosotomy as epilepsy surgery. Indications are drug-resistant generalized, diffuse, or multifocal epilepsies. A resectable seizure onset zone should be excluded. Most treated patients are diagnosed as Lennox-Gastaut or Lennox-like syndrome.

Conclusions. In cases with callosal abnormalities and clinical symptoms additional malformations are frequently observed, especially with seizure disorders. Callosotomy is the most effective option against drop attacks. The method probably is underused. After callosotomy a circumscript seizure focus might be unveiled and a second step of resective epilepsy surgery can be successful.

Key words: corpus callosum • agenesis of corpus callosum • additional malformations • seizure disorders $\cdot$ callosotomy $\cdot$ disconnection syndrome

\section{INTRODUCTION}

Corpus callosum (CC) is the largest forebrain commissure. Structural anomalies and accompanying clinical symptoms are not in the focus of neurologists, epileptologists or neurosurgeons.

\section{AIM AND METHOD}

Anatomy, embryological development, normal functions, structural abnormalities, additional malformations, clinical symptoms and seizure disorders with CC anomalies are reviewed from the literature sampled during the last ten years and completed by an extensive search within "Elektronische Zeitenschriftenbibliothek" of the Medical University of Innsbruck.

\section{REVIEW}

\section{Anatomy of corpus callosum}

Corpus callosum is by far the largest forebrain commissure with a cross sectional area of between 500 to $600 \mathrm{~mm}^{2}$. About 190 million axons cross the midline 
(Raybaud, 2010). Gross anatomy exhibits a considerable variability with the overall size related to forebrain volume (Jäncke et al., 1997). Furthermore, morphology varies with handedness (Josse et al., 2008) and with age (Suganthy et al., 2003; Garel et al., 2011; Griebe et al., 2011). Conflicting results relate to gender differences (Bishop and Wahlsten, 1997).

\section{Embryology and post-partum development}

Rakic and Yakovlev (1968) were the first to study the embryological development of cerebral commissures. At 6-to 8- weeks postconceptional age tissue bridging the midline thickens and develops into two distinct areas. The more ventral part will become the septal area and anterior commissure, the dorsal part forms the fornix, hippocampal commissure, CC and septum pellucidum. Different cellular and molecular mechanisms regulate development (Richards et al., 2004; Paul, 2011). Axons are guided by glial cells (Silver, 1993; Shu and Richards, 2001). Pioneering cingulate axons play a crucial role (Rash and Richards, 2001).

Up to three years after birth the size of CC increases rapidly followed by a slower growth until the middle 20s (Garel et al., 2011). In general, CC shrinks with the aging process. The borders between age-related asymptomatic CC thinning and functional decline are fluent.

\section{Normal functions}

Bilateral manual and finger movements are governed by interhemispheric transfer (de Guise et al., 1999; Eliassen et al., 2000; Stancák et al., 2003) and adapted to bilateral sensory (Caillé et al., 2005) as well as auditory modalities (Lessard et al., 2002; Quigley et al., 2003). CC plays a role in the integration of binocular visual information (Aglioti et al., 1993). Hemispheric specialization of language and handedness depend on transcallosal interplay (Witelson, 1985; Funnell et al., 2000; Sammler et al., 2010). Emotion, behavior (Paul et al., 2007), cognition, learning (Suganthy et al., 2003; Peltier et al., 2012), perception of causality and integrated sense of self (Gazzaniga, 2005) are influenced by transcallosal coordination.

\section{Developmental structural abnormalities}

Developmental anomalies are classified as dysgenetic, dysplastic and atrophic alterations. Totally absent commissural structures result in complete agenesis, whereas in partial agenesis the commissural plate is short but essentially complete (Paul et al., 2007; Raybaud, 2010).
Complete AgCC (agenesis of corpus callosum) is divided into type 1 and 2 (Schell-Apacik et al., 2008). With type 1 , axons are formed but unable to cross the midline. They migrate along the medial hemispheric wall and form aberrant fibre bundles known as Probst bundle. With type 2, no axons are built and no Probst bundles are seen.

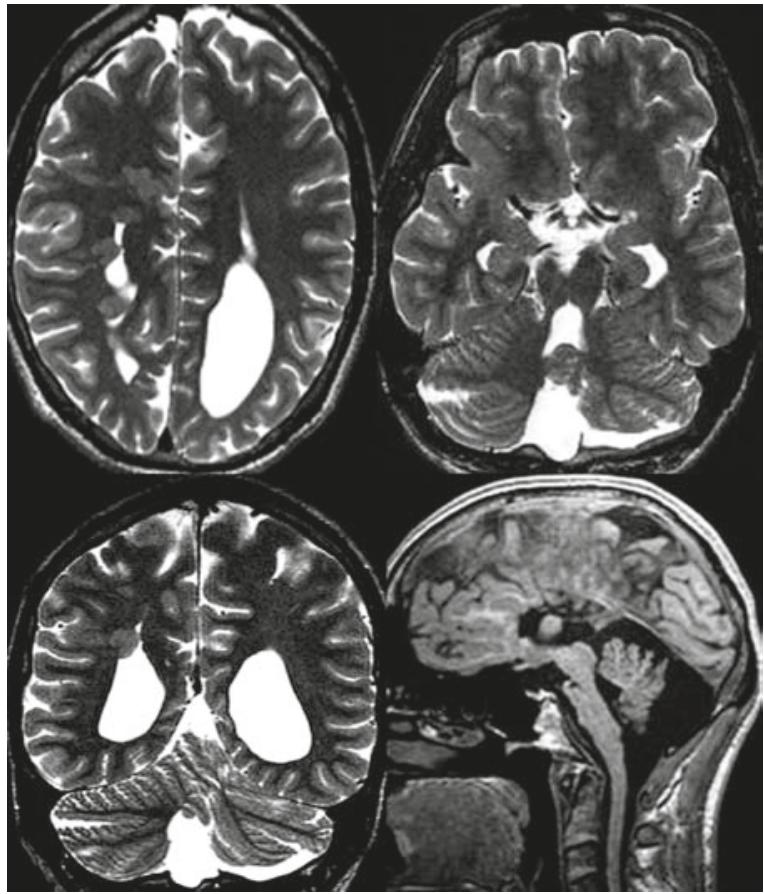

Figure 1. Severe intractable epilepsy with mixed seizure types. MRI shows AgCC, periventricular heterotopia, hypoplastic cerebellar vermis, enlarged IV ventricle, atrophic pons. Example of AgCC with additional midline and telencephalic malformations.

\section{Associated malformations with AgCC}

Additional malformations of midline and/or telencephalic nervous structures as well as changes of other organs are numerous (Figure 1). Tables 1-3 show an overview. AgCC without substantial involvement of other areas is rarely reported. These cases exhibit subtle or no clinical symptoms and do not come into medical attention. Therefore, the low incidence might be due to a selection bias (Hetts et al., 2006).

Kuchukhidze et al. (2013) as well as Doherty et al. (2013) analyzed midbrain-hindbrain malformations in patients with malformations of cortical development and epilepsy. Twenty six\% of patients with additional midbrain-hindbrain malformations exhibited callosal dysgenesis. 
Table 1. Malformations of midline structures additional to CC anomalies

\begin{tabular}{ll}
\hline Malformation & References \\
\hline Holoprosencephaly & Barkovich and Norman, 1988; Barkovich, 1990; Schell-Apacik et al., 2008; Raybaud, 2010 \\
\hline Chiari - Malformation & $\begin{array}{l}\text { Osborn, 1982; Barkovich and Norman, 1988; Glass et al., 2008; Schell-Apacik et al., 2008; } \\
\text { Larsen and Raybaud, 2010; }\end{array}$ \\
\hline Dandy-Walker Syndrom & Larsen and Osborn, 1982; Barkovich and Norman, 1988; Schell-Apacik et al., 2008 \\
\hline Interhemispheric cysts & Larsen and Osborn, 1982; Mori, 1992; Barkovich et al., 2001; Raybaud, 2010 \\
\hline Cerebellar dysgenesis & Hetts et al., 2006; Glass et al., 2008; O'Driscoll et al., 2010; Pisano et al., 2012 \\
\hline Brain stem anomalies & Hetts et al., 2006; Glass et al., 2008 \\
\hline Septum pellucidum malformations & Raybaud, 2010 \\
\hline Noncallosal midline anomalies (unspecified) & Hetts et al., 2006 \\
\hline
\end{tabular}

Table 2. Telencephalic malformations additional to CC anomalies

\begin{tabular}{ll}
\hline Malformation & References \\
\hline Lissencephaly & $\begin{array}{l}\text { Barkovich and Norman, 1988; Dobyns et al., 1999; Bonneau et al., 2002; Hetts et al., 2006; Schell- } \\
\text {-Apacik et al., 2008; Kara et al., 2010; Raybaud, 2010; Bravo et al., 2012 }\end{array}$ \\
\hline Pachygyria & Barkovich and Norman, 1988; Sztriha et al., 1998; Hetts et al., 2006; Schell-Apacik et al., 2008 \\
\hline Gray matter heterotopia & $\begin{array}{l}\text { Barkovich and Norman, 1988; Hetts et al., 2006; Schell-Apacik et al., 2008; Pisano et al., 2012; } \\
\text { González et al., 2013 }\end{array}$ \\
\hline Schizencephaly & Barkovich and Norman, 1988; Hetts et al., 2006 \\
\hline Polymicrogyria & Hetts et al., 2006; Schell-Apacik et al., 2008; O'Driscoll et al., 2010; Raybaud, 2010; Costa Nunes \\
\hline Focal cortical dysplasia & Raybaud, 2010 \\
\hline Cortical malformations (unspecified) & Hetts et al., 2006; Glass et al., 2008 \\
\hline
\end{tabular}

Table 3. Malformations of other organs in subjects with CC anomalies

\begin{tabular}{ll}
\hline Organ & References \\
\hline Genitalia & $\begin{array}{l}\text { Dobyns et al., 1999; Bonneau et al., } \\
\text { 2002; Glass et al., 2008 }\end{array}$ \\
\hline Cardiac & Glass et al., 2008 \\
\hline Musculosceletal & Glass et al., 2008 \\
\hline Gastrointestinal & Glass et al., 2008 \\
\hline Vascular & Glass et al., 2008 \\
\hline Scull deformities & Larsen and Osborn, 1982 \\
\hline Kidney & Gupta and Lilford, 1995 \\
\hline Eyes & Gupta and Lilford, 1995 \\
\hline
\end{tabular}

\section{Prevalence of AgCC}

A single incidence/prevalence number is difficult to indicate owing to the complexity of conditions with AgCC, different sample composition/size, methods used and to underrepresentation of cases not coming to medical attention. Larsen and Osborn (1982) reported an incidence of $0.1-0.3 \%$ in an unselected hospital population. In a comprehensive data base of a single academic pediatric neurology practice, AgCC was identified in $0.35 \%$ of patients (Shevell, 2002). Consecutive
MRI scans exhibited AgCC in 1.5-1.6\% (McLeod et al., 1987; Bodensteiner et al., 1994). In children with developmental abnormalities, AgCC was observed in $2-3 \%$ of children (Bedeschi et al., 2006). After exclusion of destructive lesions or other CNS malformations a population-based study found a prevalence of 1.8 per 10000 live birth for agenesis or hypoplasia of CC (Glass et al., 2008).

Subtle changes in size and shape of CC can be detected by MRI comparing groups of patients and controls. However, the incidence of these subtle CC anomalies is unknown.

\section{Etiological factors for CC anomalies}

\section{Exogenous factors (table $4 a$ and $4 b$ )}

In $30-45 \%$ of cases of AgCC identifiable causes have been reported (Paul et al., 2007). Table $4 \mathrm{a}$ and $4 \mathrm{~b}$ list identifiable etiological factors for callosal abnormalities as well as CC changes secondary to a known basic disease. One of the most frequently reported risk factor for a small CC is that of very preterm birth. Metabolic diseases are caused by a combination of exogenous and inherited factors. Acquired structural CC abnormali- 
Table 4a. Callosal anomalies secondary to known exogenous factors or basic diseases

\begin{tabular}{|c|c|c|}
\hline Exogenous factor/ basic disease & Type of CC anomaly & References \\
\hline \multirow[t]{2}{*}{ Born very preterm } & Reduced size, altered microstructure & $\begin{array}{l}\text { Stewart et al., 1999; Nosarti et al., 2004; Andersen et al., } \\
\text { 2006; Kontis et al., 2009; Aukland et al., } 2011\end{array}$ \\
\hline & $\mathrm{AgCC}$ & Glass et al., 2008 \\
\hline Normal aging & Reduced size & Ryberg et al., 2008; Griebe et al., 2011 \\
\hline DAT & $\downarrow$ thickness in different areas of CC, $\downarrow$ FA & $\begin{array}{l}\text { Hampel et al., 1998; Tomimoto et al., 2004; DiPaola et } \\
\text { al., } 2010\end{array}$ \\
\hline Cognitive disorders $\mathrm{MCl}$ & $\downarrow$ size posterior regions CC & Hensel et al., 2002 \\
\hline FTD, PSP & $\downarrow$ total callosal/skull area ratio & Yamauchi et al., 2000 \\
\hline \multirow[t]{2}{*}{ Traumatic brain injury } & $\begin{array}{l}\text { Reduction in fractional anisotropy, } \\
\text { reduced size }\end{array}$ & $\begin{array}{l}\text { Mc Leod et al., 1987; Ewing-Cobbs et al., 2006; Levin et } \\
\text { al., } 2000\end{array}$ \\
\hline & Diffuse axonal injury & Friese et al., 2000 \\
\hline Spastic cerebral palsy & Reduced CC/internal scull surface ratio & Kulak et al., 2007 \\
\hline Amyotrophic Lateral Sclerosis & $\begin{array}{l}\downarrow \text { total callosal/ skull area ratio, more } \\
\text { pronounced in patients with cognitive } \\
\text { decline }\end{array}$ & Yamauchi et al., 1995 \\
\hline
\end{tabular}

FA - Fractional anisotropy, DAT - Dementia Alzheimer type, $\mathrm{MCl}$ - Mild cognitive impairment, FTD - Fronto-temporal dementia, PSP - Progressive supranuclear palsy

Table 4b. Callosal anomalies secondary to known exogenous factors or basic diseases

\begin{tabular}{|c|c|c|}
\hline Exogenous/ basic disease & Type of CC anomaly & References \\
\hline \multirow{3}{*}{ Multiple Sclerosis } & Loss of axons, autoptic study & Evangelou et al., 2000 \\
\hline & $\downarrow$ Fractional anisotropy in subregions & Hasan et al., 2005 \\
\hline & MS-plaques in CC & Friese et al., 2000 \\
\hline Huntington disease & Reduced size & Di Paola et al., 2012 \\
\hline \multirow[t]{2}{*}{ Vascular disease } & $\begin{array}{l}\text { Encephalomalacic changes, lacunar } \\
\text { infarction, extensive leukoaraiosis }\end{array}$ & $\begin{array}{l}\text { Yamauchi et al., 1994; Giroud and Dumas, 1995; Friese et } \\
\text { al., 2000; Kim et al., } 2012\end{array}$ \\
\hline & Cavernous angioma & Katoh et al., 2013 \\
\hline $\begin{array}{l}\text { Metabolic disorders (inherited and/ } \\
\text { or acquired) }\end{array}$ & $\mathrm{AgCC}+$ other cerebral malformations & $\begin{array}{l}\text { Bamforth et al., 1988; Dobyns, 1989; Nissenkorn et al., } \\
\text { 2001; Shevell, 2002; Richards et al., } 2004\end{array}$ \\
\hline Fetal alcohol syndrome, alcoholism & $\begin{array}{l}\text { Reduced callosal area + displacement, } \\
\text { disrupted microstructure }\end{array}$ & Sowell et al., 2001 \\
\hline $\begin{array}{l}\text { Cocaine and other street drugs expo- } \\
\text { sure in utero }\end{array}$ & AgCC + other malformations & Dominguez et al., 1991 \\
\hline Child neglect & Reduced size & Teicher et al., 2004 \\
\hline Brain tumor, lymphoma, metastasis & Enhanced lesions & Friese et al., 2000 \\
\hline
\end{tabular}

ties include ischemia, other vascular changes (figure 2a), trauma, hydrocephalus, multiple sclerosis (MS), lymphoma, brain tumors and Wallerian degeneration secondary to cortical lesions (Friese et al., 2000).

Genetics

To date, no linked genes have been identified in isolat- ed AgCC. However, in combinations with other CNSmalformations a multitude of causative gene loci have been determined. The mode of inheritance can be autosomal dominant, autosomal recessive or X-linked (Richards et al., 2004; Paul et al., 2007; Schell-Apacik et al., 2008; O’Driscoll et al., 2010; Hanna et al. 2011). Aicardi described a chromosomally inherited disor- 
der with AgCC as cardinal symptom in combination with other, frequently lethal malformations (Kroner et al., 2008). Dysgenesis of CC, other brain anomalies, distinctive EEG and seizures form an entity in the $6 \mathrm{q}$ terminal deletion syndrome (Elia et al., 2006). Malformations including AgCC might also be caused by de novo mutations (Sherr et al., 2005; Shimojima et al., 2012).

\section{Clinical symptoms in cases with CC anomalies}

Statistical correlations of subtle CC changes to psychic/ neurologic abnormalities have to be separated from symptoms in cases with absent or grossly reduced CC. Tables $5 \mathrm{a}$ and $5 \mathrm{~b}$ summarize clinical symptoms in combination with CC anomalies. Cognitive dysfunctions are listed together.

The impact of CC anomalies per se is difficult to determine except for isolated CC pathologies. The classic disconnection syndrome includes disturbances of the supplementary motor area, alien hand syndrome, dichotic listening suppression, tactile dysnomia, hemispatial neglect, nondominant hand agraphia, alexia without agraphia, dysarthria and tachistoscopic visual suppression (Jea et al., 2008). Interhemispheric disconnection syndromes were observed after anterior callosal haemorrhage (Leiguarda et al., 1989) and after ischemic lesions (Giroud and Dumas, 1995; Chung et al., 2013). Neurological symptoms after surgical callosotomies in epilepsies are summarized below.

\section{Seizures and AgCC}

Numbers of patients with seizures are difficult to interpret because of additional brain abnormalities in most cases. Percentages vary between $27.3 \%$ and $89 \%$ (Taylor and David, 1998; Shevell, 2002; Doherty et al., 2006; Schell-Apecik et al., 2008). Corresponding reports in cases with isolated AgCC cannot be found. Febrile seizures (Moutard et al., 2003), infantile spasms (Khanna et al., 1994; Li et al., 2007; Conti et al., 2011; Shimojina et al., 2012), Lennox-Gastaut syndrome (Pisano et al., 2012) and several types of focal seizures with or without secondary generalization are described (Taylor and David, 1998; Luef et al.,1992; Pisano et al., 2012; Cordelli et al., 2013). Most reports relate to intractable epilepsies in complex syndromes. Seizures types and severity of epilepsy depend on additional CNS abnormalities and not on AgCC per se. In rare cases CC anomaly represents an accidental finding without a clear-cut causal relation to the epilepsy syndrome (figures $2 a$ and $2 b$ ).

\section{Transitional MRI changes in CC in epileptic patients} Single case reports and series describe small ovoid focal MRI changes in CC of epileptic patients (Kim et al., 1999; Polster et al., 2001; Cohen-Gadol et al., 2002; Feitová et al., 2002; Mirsatari et al., 2003; Prilipko et al., 2005; Gürtler et al., 2005; Gröppel et al., 2009). These lesions are transient and reversible without persistent consequences. Etiological factors like cytotoxic edema due to seizures, intoxications with AEDs, AED with-

Table 5a. Clinical symptoms with callosal abnormalities (excluding seizures)

\begin{tabular}{|c|c|c|}
\hline Symptom & Type of CC anomaly & References \\
\hline \multirow{3}{*}{ ADHD } & $\downarrow$ size genu and splenium & Paul, 2011 \\
\hline & $\mathrm{AgCC}$ & Doherty et al., 2006 (6.9\% exhibit ADHD) \\
\hline & $\downarrow$ size overall and in subdivisions & Egaas et al., 1995; Saitoh et al., 1995; Piven et al., 1997; Hardan et al., 2000 \\
\hline \multirow[t]{3}{*}{ Autism } & Changes in microstructure & Alexander et al., 2007 \\
\hline & $\mathrm{AgCC}$ & Doherty et al., 2006 (8.5\% exhibit autism) \\
\hline & $\downarrow$ size in different regions & Duara et al., 1991 \\
\hline \multirow[t]{3}{*}{ Dyslexia } & $\mathrm{AgCC}$ & Paul et al., 2003 \\
\hline & AgCC + dysgenesis CC & Schell-Apacik et al., 2008 (88\% exhibit dyslexia) \\
\hline & AgCC, dysgenesis CC & Schell-Apacik et al., 2008 (84\% exhibit feeding difficulties) \\
\hline Feeding difficulties & $\begin{array}{l}\text { AgCC }+ \text { other malformations of mid- } \\
\text { line structures }\end{array}$ & Ng et al., 2004 \\
\hline Sleep disorder & $\mathrm{AgCC}$ & Nielsen et al., 1992 \\
\hline
\end{tabular}


Table 5 b. Clinical symptoms with callosal abnormalities (excluding seizures)

\begin{tabular}{|c|c|c|}
\hline Symptom & Type of CC anomaly & References \\
\hline \multirow{2}{*}{ Cognitive deficits } & $\begin{array}{l}\text { AgCC + additional malformations } \\
\text { (not specified) }\end{array}$ & Brown and Paul, 2000; Shevell, 2002; Schell-Apacik et al., 2008 (89\%) \\
\hline & Isolated AgCC & Paul et al., 2007 (little impact) \\
\hline \multirow[t]{2}{*}{ Behavioral problems } & $\begin{array}{l}\mathrm{AgCC}+\text { additional malformations } \\
\text { (not specified) }\end{array}$ & Brown and Paul, 2000 \\
\hline & Isolated AgCC & Moutard et al., 2003 \\
\hline \multirow{3}{*}{ Schizophrenia } & $\uparrow$ callosal thickness (autoptic study) & Bigelow et al., 1983 \\
\hline & $\downarrow$ CC area & $\begin{array}{l}\text { Rossi et al., 1989; Woodruff et al., } 1995 \text { (Metaanalysis); Keshavan et al., } \\
\text { 2002; Narr et al., } 2002\end{array}$ \\
\hline & $\mathrm{AgCC}$ & David et al., 1993 \\
\hline \multirow[t]{2}{*}{ Motor symptoms } & $\mathrm{AgCC}+$ additional malformations & $\begin{array}{l}\text { Jakobson et al., 1994; Shevell, } 2002 \text { (37.5\%); Schell-Apacik et al., } 2008 \\
\text { (91\% abnormal muscle tone) }\end{array}$ \\
\hline & Isolated AgCC & Hines et al., 2002 ( $\downarrow$ visual attention) \\
\hline \multirow{2}{*}{$\begin{array}{l}\text { Oculomotor and/or } \\
\text { visual disturbances }\end{array}$} & AgCC, Dysgenesis CC & Schell-Apacik et al., 2008 (60\% visual problems) \\
\hline & $\mathrm{AgCC}+$ major CNS-malformations & Li et al., 2007 (optic coloboma) \\
\hline \multirow{2}{*}{ Tourette syndrome } & $\mathrm{FA} \downarrow$ & Cavanna et al., 2010 \\
\hline & FA $\downarrow$, size $\downarrow$ & Plessen et al., 2006 \\
\hline
\end{tabular}

FA - Fractional anisotropy

drawal, and status epilepticus among others have been discussed. Gröppel et al. (2009) investigated a series of 24 out of 1050 patients and found no statistically significant relation to any of these variables.

Similar transient CC anomalies have been observed with non-epileptic conditions like encephalitis/encephalopathy (Tada et al., 2004; Yaguchi et al., 2005; Bulakbasi et al., 2006; Sreedharan et al., 2011), AED intake in depressive patients without epilepsy (Maeda et al., 2003), brain radiation (Pekala et al., 2003) and other multiple conditions (Doherty et al., 2006; Maeda et al., 2006). Therefore, transient MRI changes in CC are unspecific and causally unexplained.

\section{Callosotomy as a treatment option}

Van Wagenen and Herren (1940) were the first to suggest a role for callosum section in epilepsy surgery. Methods used are anterior, posterior and total commissurotomy whether in a one-step or a two-step procedure (Fuiks et al., 1991; Cendes et al., 1993; Spencer et al., 1993; Rahimi et al., 2007; Rathore et al., 2007; Tanriverdi et al., 2009). In recent times, radiosurgical callosotomy has been performed (Feichtinger et al., 2006; Bodaghabadi et al., 2011; Moreno-Jiménez et al., 2012).
Indications remain somewhat controversial. Medical intractability and exclusion of a seizure onset zone amenable for resective surgery are considered a prerequisite. Early and recent studies concentrate on intractable generalized seizure types especially drop attacks (Oguni et al., 1991; Carmant et al., 1998; Maehara and Shimuzu, 2001; Majkowska-Zwolinska, 2002; Rathore et al., 2007; Iwasaki et al., 2011). With regard to epilepsy syndromes secondarily generalized epilepsies (Rappaport and Lerman, 1988), Lennox-Gastaut syndrome or Lennox-like syndromes (Kwan et al., 2005; Cukiert et al., 2006), West syndrome (Pinard et al., 1999; Rahimini et al., 2007), and intractable idiopathic generalized epilepsies (Jensen et al., 2006; Iimura et al., 2012) are included. Epilepsies due to bihemispheric cortical dysplasias have also been treated (Landy et al., 1993; Pallini et al., 1995; Vossler et al., 1999; Kawai et al., 2004). The common determinants are medical intractability of severe and disabling drop seizures, best summarized under the term Lennox-Gastaut syndrome.

Outcome of callosotomy by seizures uniformly stresses the good to excellent improvement of drop seizures (Rappaport and Lerman, 1988; Oguni et al., 1991; Cendes et al., 1993; Spencer et al., 1993; Sakas and Phil- 


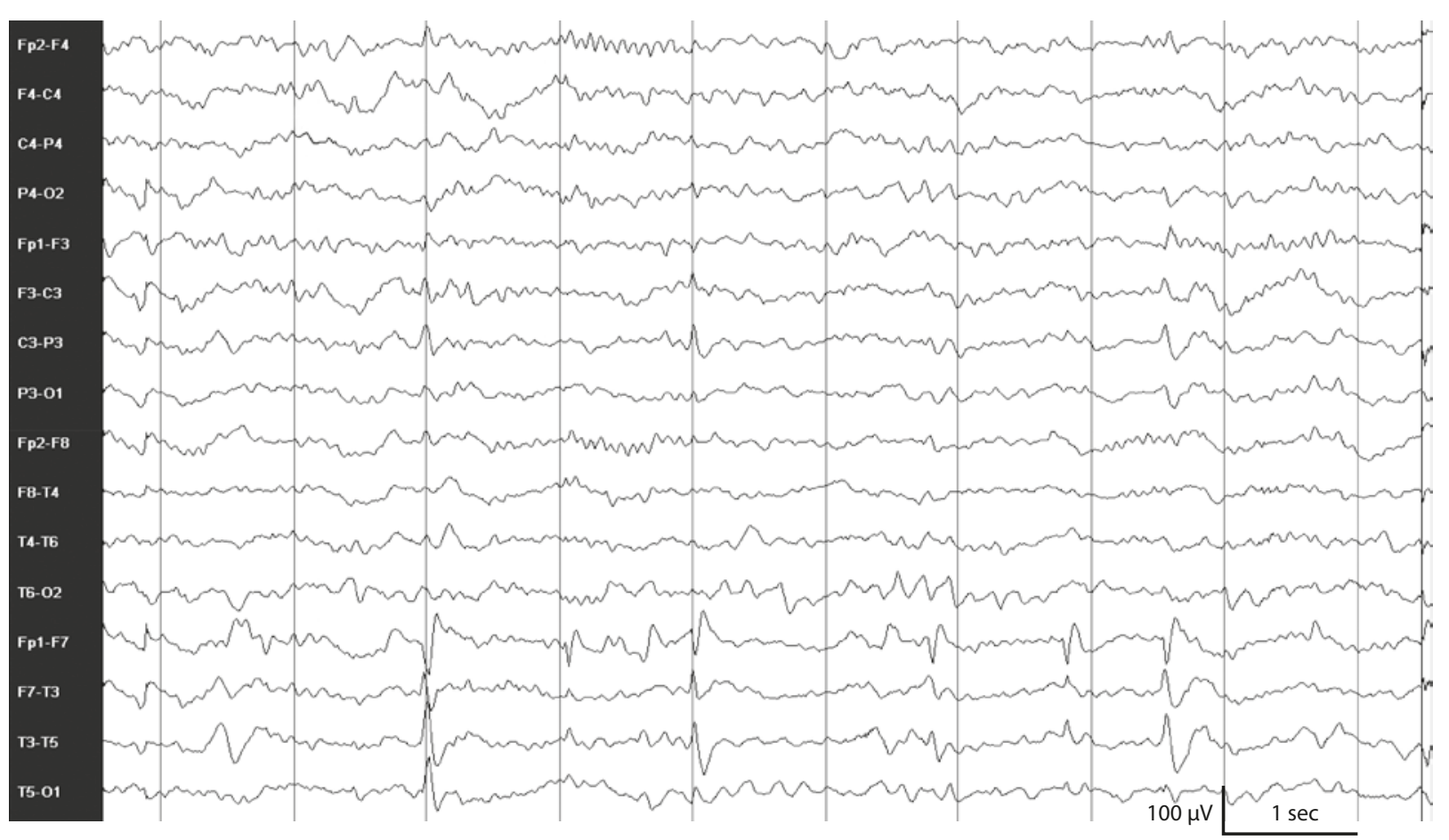

Figure 2a. Female, 32 years, L-sided temporal lobe epilepsy. Segment of EEG-video recording. Sleep record, sharp wave focus over F7, T3.

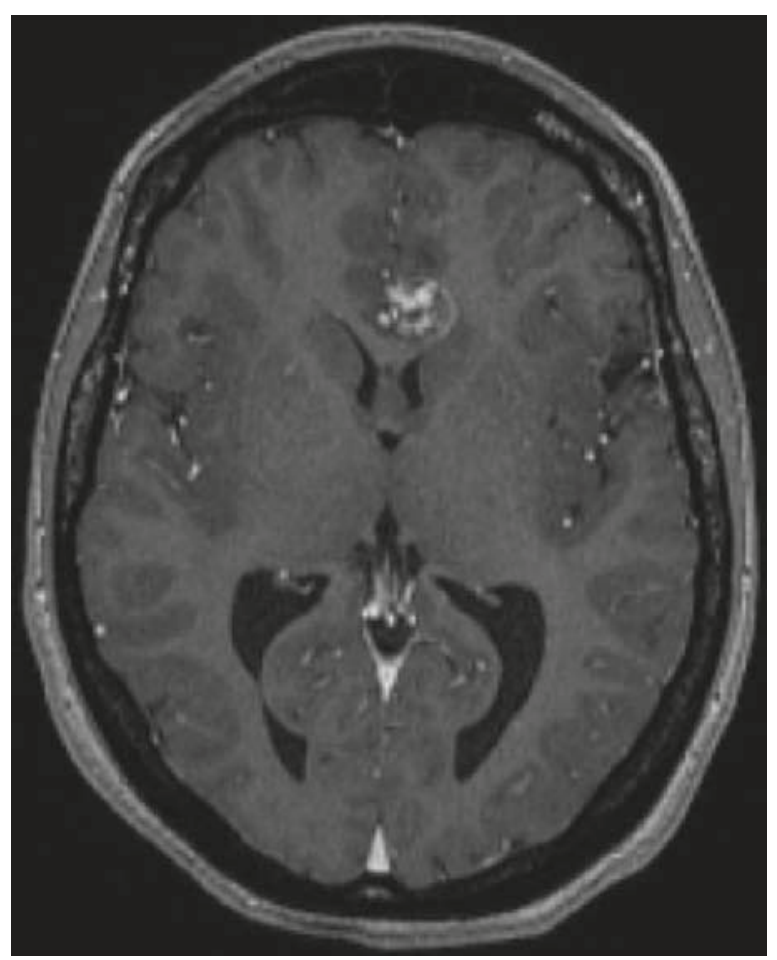

Figure 2 b. Female, 32 years, L-sided temporal lobe epilepsy. MRI shows a cavernous agioma within the CC, considered an accidental finding without a causal relationship to temporal lobe epilepsy. lips, 1996; Pinard et al., 1999; Maehara and Shimuzu, 2001; Cukiert et al., 2006; Rathore et al., 2007). Follow-up studies demonstrated a long-lasting reduction of drop seizures (Sunaga et al., 2009; Tanriverdi et al., 2009). To a lesser degree other generalized seizure types and partial seizures are also improved. Callosotomy represents an effective measure against severe drop attacks. Although patients free of drop seizures are reported, the method has to be regarded as a palliative strategy.

Besides seizure-reducing efficacy, several other positive effects have been reported. Improvements in behavior, attention, overall daily and cognitive functions are observed (Cendes et al., 1993; Maehara and Shimuzu, 2001; Cukiert et al., 2006; Rahimi et al., 2007; Rathore et al., 2007; Yonekawa et al., 2011). Correspondingly, quality of life measures improve (Andersen et al., 1996; Carmant et al., 1998), and parents of patients are satisfied by the postoperative outcome (Gilliam et al., 1996; Yang et al., 1996; Sassower et al., 2001; Rathore et al., 2007).

Neurological symptoms after callosotomy mostly are mild and transient, and include parts of the classical disconnection syndrome (Sass et al., 1990; Fuiks et al., 1991; Andersen et al., 1996; Lausberg et al., 2003). In 
cases of total sections symptoms are more frequent and can persist (Provinciali et al., 1990; Cendes et al., 1993).

Preoperative EEG changes reflect the selection of patients. Generalized epileptiform discharges like spikes and waves, 2/sec sharp and slow waves, runs of rapid spikes (figure 3a), and generalized ictal patterns have been recorded (Spencer et al., 1993; Oguni et al. 1994; Phillips and Sakas, 1996; Hanson et al., 2002; Kwan et al., 2005; Cukiert et al., 2006). After commissurotomy, disruption of generalized discharges or their complete elimination was observed in the majority of patients (Gates et al., 1984; Spencer et al., 1985; Oguni et al., 1994; Kwan et al., 2005; Cukiert et al., 2006). In about half of patients, the postoperative EEG exhibited a delineated spike focus (Iwasaki et al., 2011; Ono et al., 2011) (figures 3a and 3b). No criteria in the preoperative EEG are known to predict outcome (Makari et al., 1989; Hanson et al., 2002). Improvement in postoperative EEG was correlated with better seizure outcome (Rathore et al., 2007; Yonekawa et al., 2011).

\section{Options after callosotomy}

Callosotomy is considered a palliative measure. Many patients remain uncontrolled even with drop attacks. After callosotomy an epileptogenic focus might be identified and confirmed as seizure onset zone by invasive methods. Consecutive resective epilepsy surgery resulted in good results (Clarke et al., 2007; Lin et al., 2011; Ono et al., 2011).

Another option in severe generalized, diffuse or multifocal epilepsies is vagus nerve stimulation. A comparison with callosotomy demonstrated a significantly better outcome for callosotomy but a higher risk for complications (Nei et al., 2006; Lancman et al., 2013). Thalamic stimulation after anterior callosotomy was moderately successful in two patients (Capecci et al., 2012).

\section{CONCLUSIONS}

Commissural abnormalities consist of developmental dys- or agenesis, acquired lesions in the CC, shrinkage

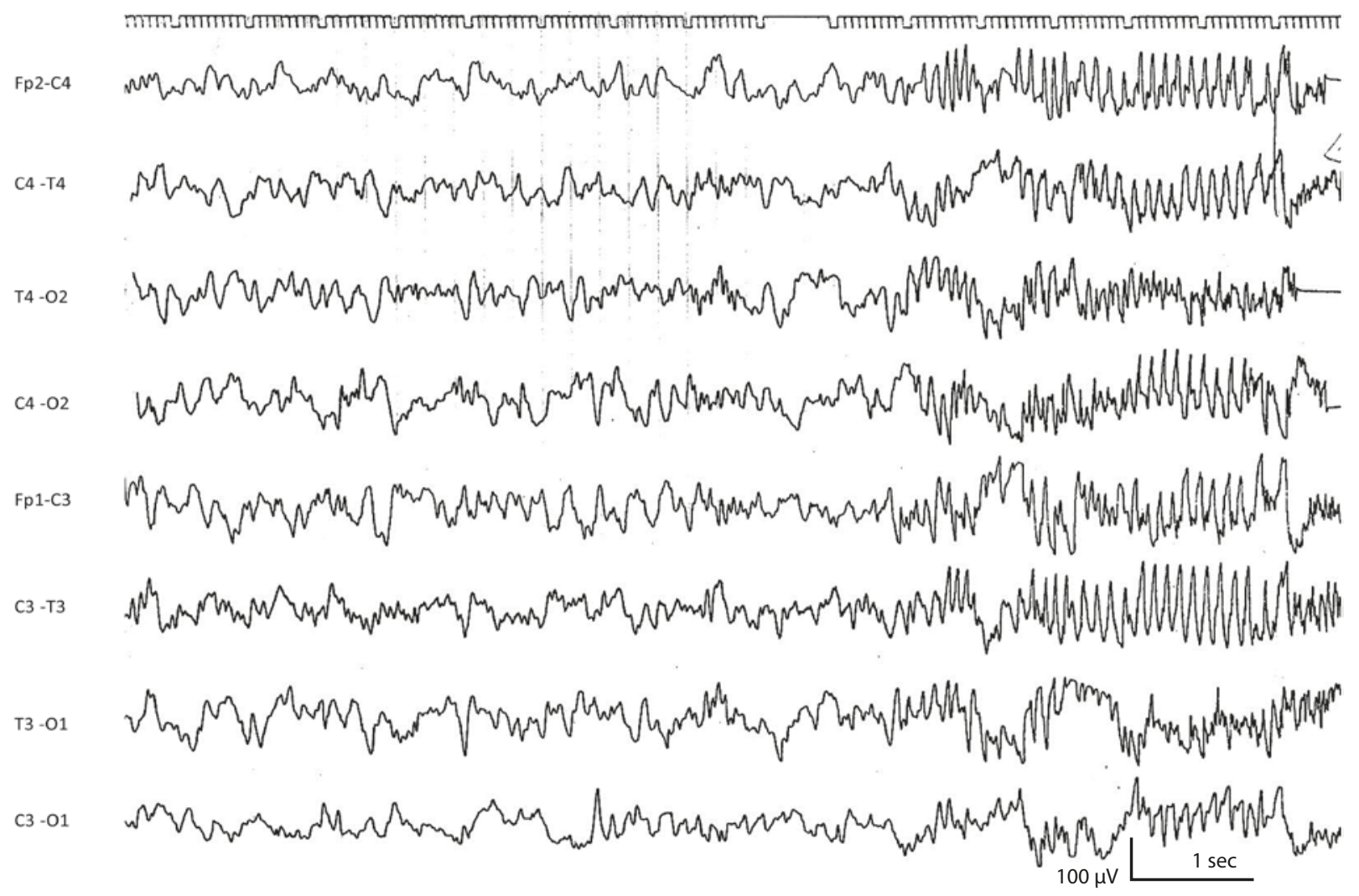

Figure 3a. Female, 24 years of age, tc $1.0 \mathrm{~F}$ 70. Lennox-Gastaut syndrome of late onset. Sleep EEG before callosotomy. Bilateral run of rapid spikes. 


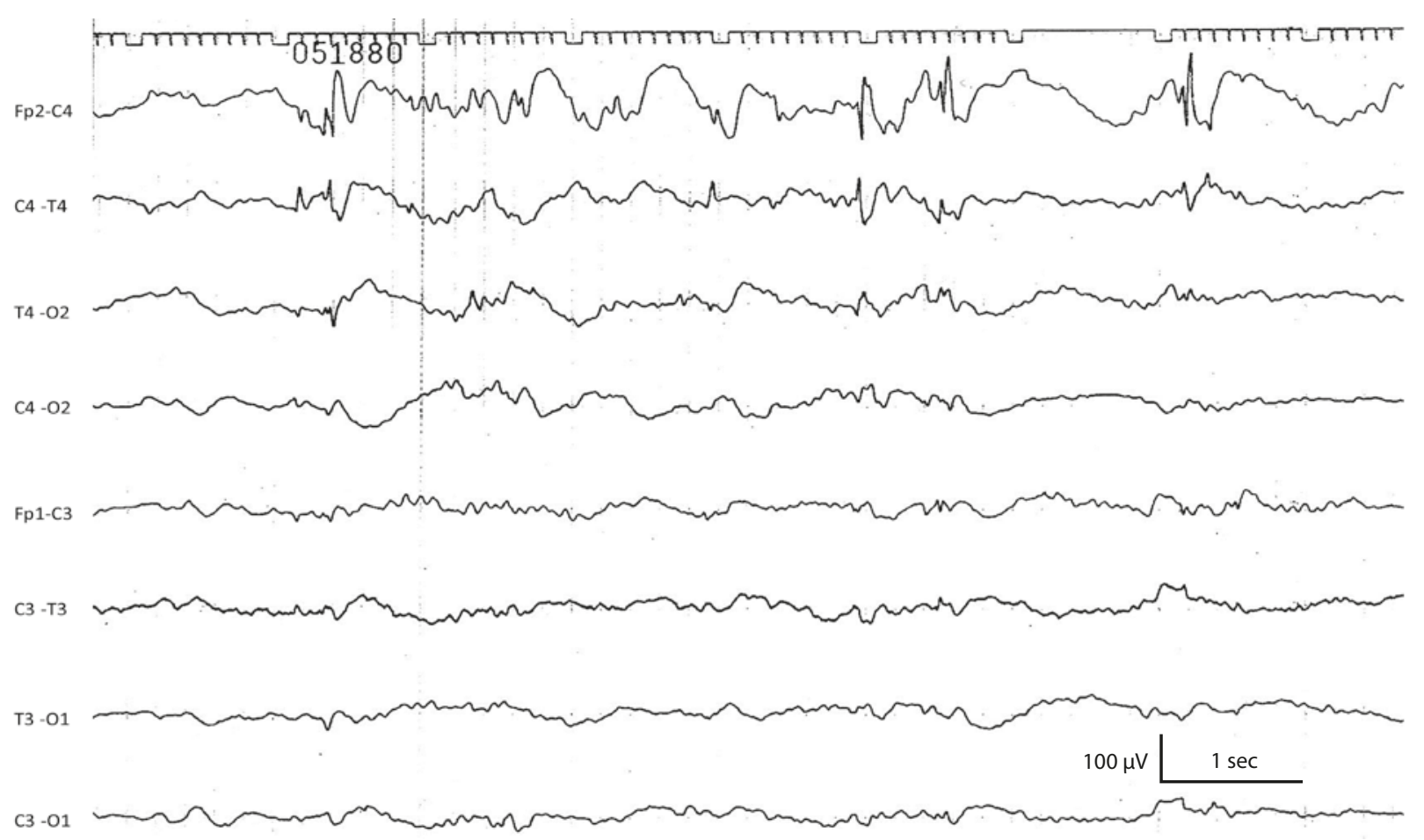

Figure 3b. Female, 24 years of age, tc $1.0 \mathrm{~F}$ 70. EEG 5 months after partial callosotomy. EEG during sleep. Spike and wave focus over C4. No bilateral epileptiform activities.

of fibres due to Wallerian degeneration secondary to forebrain lesions and subtle statistical group changes.

Developmental CC anomalies are part of more extended dysplastic lesions of midline and telencephalic structures in the overwhelming number of cases with neurological symptoms. Specialized imaging studies should be performed to demonstrate these causative lesions.

Subtle group changes in the size and structure of CC are seen with a number of conditions (tables $4 \mathrm{a}, 4 \mathrm{~b}$ and 5). The clinical significance of these statistical correlations is unknown.

Epileptic seizures are seen in up to $89 \%$. Seizure types and epilepsies include a variety of focal and generalized disorders and are caused by malformations additional to AgCC.

Surgical callosotomy has been used in untreatable severe epilepsy syndromes not amenable for resective surgery. Most patients suffered multiple seizure types with prominent drop seizures, corresponding to Lennox-Gastaut or Lennox-like syndromes. Outcome after callosotomy is best for drop seizures although no entirely seizure free patients can be expected. With the introduction of new antiepileptic drugs and vagal nerve stim- ulation the use of callosotomy has decreased. Although callosotomy has a higher risk for complications, the effect on seizure frequency seems to be more pronounced and the procedure is probably underused. The role of callosotomy as a method to unveil a masked resectable seizure focus has to be corroborated by a formal study.

\section{CONFLICT OF INTEREST DISCLOSURE}

The authors have no conflict of interest to declare.

\section{REFERENCES}

Aglioti S., Berlucchi G., Pallini R., Rossi G.F., Tassinari G.: Hemispheric control of unilateral and bilateral responses to lateralized light stimuli after callosotomy and in callosal agenesis. Exp. Brain Res., 1993, 95: 151-165.

Alexander A.L., Lee J.E., Lazar M., Boudos R., DuBray M.B., Oakes T.R. et al.: Diffusion tensor imaging of the corpus callosum in autism. Neuroimage, 2007, 34: 61-73.

Andersen B., Rogvi-Hansen B., Kruse-Larsen C., Dam M.: Corpus callosotomy: Seizure and psychosocial outcome. A 39-month follow-up of 20 patients. Epil. Res., 1996, 23: 77-85. Anderson N.G., Laurent I., Woodwart L.J., Inder T.E.: Detection of impaired growth of the corpus callosum in premature infants. Pediatrics, 2006, 118: 951-960. 
Aukland S.M., Westerhausen R., Plessen K.J., Odberg M.D., Elgen I.B., Peterson B.S. et al.: Selectively reduced posterior corpus callosum size in a population-based sample of young adults born with low birth weight. AJNR, 2011, 32: 970-975. Bamforth F., Bamforth S., Poskitt K., Applegarth D., Hall J. et al.: Abnormalities of corpus callosum in patients with inherited metabolic diseases. Lancet, 1988, 332: 451.

Barkovich A.J.: Apparent atypical callosal dysgenesis: analysis of MR findings in six cases and their relationship to holoprosencephaly. AJNR, 1990, 11: 333-340.

Barkovich A.J. and Norman D.: Anomalies of the corpus callosum: Correlation with further anomalies of the brain. Am. J. Roentgenol., 1988, 151: 171-179.

Barkovich A.J., Simon E.M., Walsh C.A: Callosal agenesis with cyst. A better understanding and new classification. Neurology, 2001, 56: 220-227.

Bedeschi M.F., Bonaglia M.C., Grasso R., Pellegri A., Garghentino R.R., Battaglia M.A. et al.: Agenesis of the corpus callosum: Clinical and genetic study in 63 young patients. Pediatr. Neurol., 2006, 34: 186-193.

Bigelow L.B., Nasrallah H.A., Rauscher F.P.: Corpus callosum thickness in chronic schizophrenia. Brit. J. Psychiat. 1983, 142: 284-287.

Bishop K.M. and Wahlsten. D: Sex differences in the human corpus callosum: Myth or reality? Neurosci. Biobehav. Rev., 1997, 21: 581-601.

Bodaghabadi M., Bitaraf M.A., Aran S., Alikhani M., Ashrafian H., Zahiri A. et al.: Corpus callosotomy with gamma knife radiosurgery for a case of intractable generalised epilepsy. Epil. Disord., 2011, 13: 202-208.

Bodensteiner J., Schaefer G.B., Breeding L., Cowan L.: Hypoplasia of the corpus callosum: A study of 445 consecutive MRI scans. J. Child. Neurol., 1994, 9: 47-49.

Bonneau D., Toutain A., Laquerrière A., Marret S., Saugier-Veber P., Barthez M.A. et al.: X-linked lissencephaly with absent corpus callosum and ambiguous genitalia (XLAG): Clinical, magnetic resonance imaging, and neuropathological findings. Ann. Neurol., 2002, 51: 340-349.

Bravo E.K., White M.L., Olney A.H., McAllister J.L., Zhang Y.D. et al.: Novel proximal $14 q$ deletion: Clinical and diffusion tensor imaging tractography findings in a patient with lissencephaly, agenesis of the corpus callosum, and septo-optic dysplasia. AJNR, 2012, 33: 16-18.

Brown W.S. and Paul L.K.: Cognitive and psychosocial defecits in agenesis of the corpus callosum with normal intelligence. Cogn. Neuropsychiatry, 2000, 5: 135-157.

Bulakbasi N., Kocaoglu M., Tayfun C., Ucoz T.: Transient splenial lesion of the corpus callosum in clinically mild influ- enza-associated encephalitis/encephalopathy. AJNR, 2006, 27: 1983-1986.

Caillé S., Sauerwein H.C., Schiavetto A., Villemure J.G., Lassonde M.: Sensory and motor interhemispheric integration after section of different portions of the anterior corpus callosum in nonepileptic patients. Neurosurgery, 2005, 57: 50-59. Capecci M., Ricciuti R.A., Ortenzi A., Paggi A., Durazzi V., Rychlicki F. et al.: Chronic bilateral subthalamic stimulation after anterior callosotomy in drug-resistant epilepsy: Longterm clinical and functional outcome of two cases. Epil. Res., 2012, 98: 135-139.

Carmant L., Holmes G.L., Lombroso C.T.: Outcome following corpus callosotomy. J. Epilepsy, 1998, 11: 224-228.

Cavanna A.E., Stecco A., Rickards H., Servo S., Terazzi E., Peterson B. et al.: Corpus callosum abnormalities in Tourette syndrome: an MRT-DTI study of monozygotic twins. J. Neurol. Neurosurg. Psychiatry, 2010, 81: 533-535.

Cendes F., Ragazzo P.C., da Costa V., Martins L.F.: Corpus callosotomy in treatment of medically resistant epilepsy: Preliminary results in a pediatric population. Epilepsia, 1993, 34: 910-917.

Chung S.J., Kim J.H., Ahn H.-J., Han Z.A., Cho J.H., Kim G.S. et al.: Callosal dysarthria. Clin. Neurol. Neurosurg., 2013, 115: 1173-1176.

Clarke D.F., Wheless J.W., Chacon M.M., Breier J., Koenig M.K., McManis M. et al.: Corpus callosotomy: A palliative therapeutic technique may help identify resectable epileptogenic foci. Seizure, 2007, 16: 545-553.

Cohen-Gadol A.A., Britton J.W., Jack C.R., Friedman J.A., Marsh W.R.: Transient postictal magnetic resonance imaging abnormality of the corpus callosum in a patient with epilepsy. J. Neurosurg., 2002, 97: 714-717.

Conti V., Marini C., Gana S., Sudi J., Dobyns W.B., Guerrini R. et al.: Corpus callosum agenesis, severe mental retardation, epilepsy, and dysgenetic quadriparesis due to a novel mutation in the homeodomain of ARX. Am. J. Med. Genet. A, 2011, 155: 892-897.

Cordelli D.M., Garavelli L., Savasta S., Guerra A., Pellicciari A., Giordano L. et al.: Epilepsy in Movat-Wilson syndrome: Delineation of the electroclinical phenotype. Am. J. Med. Genet., 2013, 161: 273-284.

Costa Nunes J.C., Ferreira Martins R., Bastos A., Claudino L.S., Guarnieri R., Lima Dde C. et al.: Brain lipoma, corpus callosum hypoplasia and polymicrogyria in Familial Multiple Lipomatosis. Clin. Neurol. Neurosurg., 2013, 115: 1157-1159. Cukiert A., Burrattini J.A., Mariani P.P., Câmara R.B., Seda L., Baldauf C.M. et al.: Extended, one-stage callosal section for treatment of refractory secondarily generalized epilepsy 
in patients with Lennox-Gastaut and Lennox-like syndromes. Epilepsia, 2006, 47: 371-374.

David A.S., Wacharasindhu A., Lishman W.A.: Severe psychiatric disturbance and abnormalities of the corpus callosum: review and case series. J. Neurol. Neurosurg. Psychiatry, 1993, 56: 85-93.

De Guise E., del Pesce M., Foschi N., Quattrini A., Papo I., Lassonde M.: Callosal and cortical contribution to procedural learning. Brain, 1999, 122: 1049-1062.

Di Paola M., Di Iulio F., Cherubini A., Blundo C., Casini A.R., Sancesario G. et al.: When, where, and how the corpus callosum changes in MCI and AD. A multimodal MRI study. Neurology, 2010, 74: 1136-1142.

Di Paola M., Luders E., Cherubini A., Sanchez-Castaneda C., Thompson P.M., Toga A.W. et al.: Multimodal MRI analysis of the corpus callosum reveals white matter differences in presymptomatic and early Huntington's disease. Cerebral Cortex, 2012, 22: 2858-2866.

Dobyns W.B.: Agenesis of the corpus callosum and gyral malformations are frequent manifestations of nonketotic hyperglcinemia. Neurology, 1989, 39: 817-820.

Dobyns W.B., Berry-Kravis E., Havernick N.J., Holden

K.R., Viskochil D.: X-linked lissencephaly with absent corpus callosum and ambiguous genitalia. Am. J. Med. Genet., 1999, 86: 331-337.

Doherty D., Millen K.J., Barkovich A.J.: Midbrain and hindbrain malformations: advances in clinical diagnosis, imaging, and genetics. Lancet Neurol., 2013, 12: 381-393.

Doherty D., Tu S., Schilmoeller K., Schilmoeller G.: Healthrelated issues in individuals with agenesis of the corpus callosum. Child: Care, Heath \& Dev., 2006, 32: 333-342.

Dominguez R., Aguirre Vila-Coro A., Slopis J.M., Bohan T.P.: Brain and ocular abnormalities in infants with in utero exposure to cocaine and other street drugs. Am. J. Dis. Child., 1991, 145: 688-695.

Duara R., Kushch A., Gross-Glenn K., Barker W.W., Jallad B., Pascal S. et al.: Neuroanatomic differences between dyslexic and normal readers on magnetic resonance imaging scans. Arch. Neurol., 1991, 48: 410-416.

Egaas B., Courchesne E., Saitoh O.: Reduced size of corpus callosum in autism. Arch. Neurol., 1995, 52: 794-801.

Elia M., Striano P., Fichera M., Gaggero R., Castiglia L., Galesi O. et al.: $6 q$ terminal deletion syndrome associated with distinctive EEG and clinical pattern: A report of five cases. Epilepsia, 2006, 47: 830-838.

Eliassen J., Baynes K., Gazzaniga S.: Anterior and posterior callosal contributions to simultaneous bimanual movements of the hands and fingers. Brain, 2000, 123: 2501-2511.

Evangelou N., Konz D., Esiri M.M. Smith S., Palace J., Mat- thews P.M.: Regional axonal loss in the corpus callosum correlates with cerebral white matter lesion volume and distribution in multiple sclerosis. Brain, 2000, 123: 1845-1849.

Ewing-Cobbs L., Hasan K.M., Prasad M.R., Kramer L., Bachevalier J.: Corpus callosum diffusion anisotropy correlates with neuropsychological outcomes in twins discordant for traumatic brain injury. AJNR, 2006, 27: 879-881.

Feichtinger M., Schröttner O., Eder H., Holthausen H., Pieper T., Unger F. et al.: Efficacy and safety of radiosurgical callosotomy: A retrospective analysis. Epilepsia, 2006, 47: 1184-1191.

Feitová V., Feit J., Krupa P.: Therapy-related change of corpus callosum in a young patient with epilepsy. Eur. Radiol., 2002, 12: 345-347.

Friese S.A., Bitzer M., Freudenstein D., Voigt K., Küker W.: Classification of acquired lesions of the corpus callosum with MRI. Neuroradiol., 2000, 42: 795-802.

Fuiks K.S.,Wyler A.R., Hermann B.P., Somes G.: Seizure outcome from anterior and complete corpus callosotomy. J. Neurosurg., 1991, 74: 573-578.

Funnell M.G., Corballis P.M., Gazzaniga M.S.: Insights into the functional specificity of the human corpus callosum. Brain, 2000, 123: 920-926.

Garel C., Cont I., Alberti C., Josserand E., Moutard M.L., Ducou le Pointe H.: Biometry of the corpus callosum in children: MR imaging reference data. AJNR, 2011, 32: 1436-1443. Gates J.R., Leppik I.E., Yap J., Gumnit R.J.: Corpus callosotomy: Clinical and electroencephalographic effects. Epilepsia, 1984, 25: 308-316.

Gazzaniga M.S.: Forty-five years of split-brain research and still going on. Nat. Rev. Neurosci., 2005, 6: 653-659.

Gilliam F., Wyllie E., Kotagal P., Geckler C., Rusyniak G.: Parental assessment of functional outcome after callosotomy. Epilepsia, 1996, 37: 753-757.

Giroud M. and Dumas R.: Clinical and topographical range of callosal infarction: a clinical and radiological correlation study. J. Neurol. Neurosurg. Psychiatry, 1995, 59: 238-242. Glass H.C., Shaw G.M., Ma C., Sherr E.H.: Agenesis of the corpus callosum in California 1983-2003: A population-based study. Am. J. Med. Genet., 2008, 146A: 2495-2500.

González G., Vedolin L., Barry B., Poduri A., Walsh C., Barkovich A.J.: Location of periventricular nodular heterotopias is related to the malformation phenotype on MRI. AJNR, 2013, 34: 877-883.

Griebe M., Förster A., Wessa M., Rossmanith C., Bäzner H., Sauer T. et al.: Loss of callosal fibre integrity in healthy elderly with age-related white matter changes. J. Neurol., 2011, 258: 1451-1459.

Gröppel G., Gallmetzer P., Prayer D., Serles W., Baum- 
gartner C.: Focal lesions in the splenium of the corpus callosum in patients with epilepsy. Epilepsia, 2009, 50: 1354-1360. Gupta J.K. and Lilford R.J.: Assessment and management of fetal agenesis of the corpus callosum. Prenatal. Diagn., 1995, 15: 301-312.

Gürtler S., Ebener A., Tuxhorn I., Ollech I., Pohlmann-Eden B., Woermann F.G.: Transient lesion in the splenium of the corpus callosum and antiepileptic drug withdrawal. Neurology, 2005, 65: 1032-1036.

Hampel H., Teipel S.J., Alexander G.E., Horwitz B., Teichberg D., Schapiro M.B. et al.: Corpus callosum atrophy is a possible indicator of region- and cell type-specific neuronal degeneration in Alzheimer disease. A magnetic resonance imaging analysis. Arch. Neurol., 1998, 55: 193-198.

Hanna R.M., Marsh S.E., Swistun D., Al-Gazali L., Zaki M.S., Abdel-Salam G.M. et al.: Distinguishing 3 classes of corpus callosal abnormalities in consanguineous families. Neurology, 2011, 76: 373-382.

Hanson R.R., Risinger M., Maxwell R.: The ictal EEG as a predictive factor for outcome following corpus callosum section in adults. Epil. Res., 2002, 49: 89-97.

Hardan A.Y., Minshew N.J., Keshavan M.S.: Corpus callosum size in autism. Neurology, 2000, 55: 1033-1036.

Hasan K.M., Gupta R.K., Santos R.M., Wolinsky J.S., Narayana P.A.: Diffusion tensor fractional anisotropy of the normal-appearing seven segments of the corpus callosum in healthy adults and relapsing-remitting multiple sclerosis patients. J. Magn. Reson. Imaging, 2005, 21: 735-743.

Hensel A., Wolf H., Kruggel F., Riedel-Heller S.G., Nikolaus C., Arendt T. et al.: Morphometry of the corpus callosum in patients with questionable and mild dementia. J. Neurol. Neurosurg. Psychiatry, 2002, 73: 59-61.

Hetts S.W., Sherr E.H., Chao S. Gobuty S., Barkovich A.J.: Anomalies of the corpus callosum: An MR analysis of the phenotypic spectrum of the associated malformations. AJR, 2006, 187: $1343-1348$

Hines R.J., Paul L.K., Brown W.S.: Spatial attention in agenesis of the corpus callosum: shifting attention between visual fields. Neuropsychologia, 2002, 40: 1804-1814.

Iimura Y., Sugano H., Nakajima M., Arai H.: Stepwise synchronization through the corpus callosum is one cause of myoclonic jerks. World Neurosurg., 2012, 77: 399, doi: 10.1016/j. wneu.2011.07.006.

Iwasaki M., Nakasato N., Kakisaka Y., Kanno A., Uematsu M., Haginoya K. et al.: Lateralization of interictal spikes after callosotomy. Clin. Neurophysiol., 2011, 122: 2121-2127.

Jakobson L.S., Servos P., Goodale M.A., Lassonde M.: Control of proximal and distal components of prehension in acallosal agenesis. Brain, 1994, 117: 1107-1113.
Jäncke L., Staiger J.F., Schlaug G., Huang Y., Steinmetz H.: The relationship between corpus callosum size and forebrain volume. Cerbral Cortex, 1997, 7: 48-56.

Jea A., Vachhrajani S., Widjaja E., Nilsson D., Raybaud C., Shroff M. et al.: Corpus callosotomy in children and the disconnection syndromes: a review. Childs Nerv. Syst., 2008, 24: 685-692.

Jensen S., Sperling M.R., Tracy J.I., Nei M., Joyce L., David G. et al.: Corpus callosotomy in refractory idiopathic generalized epilepsy. Seizure, 2006, 15: 621-629.

Josse G., Seghier M.L., Kherif F., Price C.J.: Explainung function with anatomy: Language lateralization and corpus callosum size. J. Neurosci., 2008, 24: 14132-14139.

Kara S., Jissendi-Tchofo P., Barkovich A.J.: Developmental differences of the major forebrain commissures in lissencephalies. AJNR, 2010, 31: 1602-1607.

Katoh M., Sawamura Y., Moriwaki T., Yoshino M., Aoki T., Abumiya T. et al.: A case of cervernous angioma in the septum pellucidum. Clin. Neurol. Neurosurg., 2013, 115: 1126-1127. Kawai K., Shimizu H., Yagishita A., Maehara T., Tamagawa K.: Clinical outcomes after corpus callosotomy in patients with bihemispheric malformations of cortical development. J. Neurosurg., 2004, 101 (Suppl): 7-15.

Keshavan M.S., Diwadkar V.A., Harenski K., Rosenberg D.R., Sweeney J.A., Pettegrew J.W.: Abnormalities of the corpus callosum in first episode naïve schizophrenia. J. Neurol. Neurosurg. Psychiatry, 2002, 72: 757-760.

Khanna S., Chugani H.T., Messa C., Curran J.G.: Corpus callosum agenesis and epilepsy: PET findings. Pediatr. Neurol., 1994, 10: 221-227.

Kim S.S., Chang K-H., Kim S.T., Suh D.C., Cheon J.E., Jeong S.W. et al.: Focal lesion in the splenium of the corpus callosum in epileptic patients: Antiepileptic drug toxicity? Am. J. Neuroradiol., 1999, 20: 125-129.

Kim H.Y., Kim J.Y., Kim Gu, Han H.J., Shin D.I.: Alien hand syndrome after epilepsia partialis continua: FDG PET and MRI studies. Epilepsy Behav., 2012, 23: 71-73.

Kontis D., Catani M., Cuddy M., Walshe M., Nosarti C., Jones D. et al.: Diffusion tensor MRI of the corpus callosum and cognitive function in adults born preterm. NeuroReport, 2009, 20: 424-428.

Kroner B.L., Preiss L.R., Ardini M-A., Gaillard W.D.: New incidence, prevalence, and survival of Aicardi syndrome from 408 cases. J. Child. Neurol., 2008, 23: 531-535.

Kuchuhidze G., Koppelstaetter F., Unterberger I., Dobesberger J., Walser G., Höfler J. et al.: Midbrain-hindbrain malformations in patients with malformations of cortical development and epilepsy: A series of 220 patients. Epil. Res., 2013, 106: 181-190. 
Kulak W., Sobaniec W., Kubas B., Walecki J.: Corpus callosum size in children with spastic cerebral palsy: Relationship to clinical outcome. J. Child. Neurol., 2007, 22: 371-374. Kwan S-Y., Lin J-H., Wong T-T., Chang K.P., Yiu C.H.: Prognostic value of electrocorticography findings during callosotomy in children with Lennox-Gastaut syndrome. Seizure, 2005, 14: 470-475.

Lancman G., Virk M., Shao H., Mazumdar M., Greenfield J.P., Weinstein S. et al.: Vagus nerve stimulation vs. corpus callosotomy in the treatment of Lennox-Gastaut syndrome: A meta-analysis. Seizure, 2013, 22: 3-8.

Landy H.J., Curless R.G., Ramsay R.E., Slater J., AjmoneMarsan C., Quencer R.M.: Corpus callosotomy for seizures associated with band heterotypia. Epilepsia, 1993, 34: 79-83. Larsen P.D. and Osborn A.G.: Computed tomographic evaluation of corpus callosum agenesis and associated malformations. J. Comput. Tomogr., 1982, 6: 225-230.

Lausberg H., Cruz R.F., Kita S., Zaidel E., Ptito A.: Pantomime to visual presentation of objects: left hand dyspraxia in patients with complete callosotomy. Brain, 2003, 126: 343-360. Leiguardia R., Starkstein S., Berthier M.: Anterior callosal haemorrhage. A partial interhemispheric disconnection syndrome. Brain, 1989, 112: 1019-1037.

Lessard N., Lepore F., Villemagne J., Lassonde M.: Sound localization in callosal agenesis and early callosotomy subjects: brain reorganization and/or compensatory strategies. Brain, 2002, 125: 1039-1053.

Levin H.S., Benavidez D.A., Verger-Maestre K., Perachio N., Song J., Mendelsohn D.B. et al.: Reduction of corpus callosum growth after severe traumatic brain injury in children. Neurology, 2000, 54: 647-653.

Li J., Shivakumar S., Wakahiro M., Mukherjee P., Barkovich A.J., Slavotinek A. et al.: Agenesis of the corpus callosum, optic coloboma, intractable seizures, craniofacial and skeletal dysmorphisms: An autosomal recessive disorder similar to Temtamy syndrome. Am. J. Med. Genet. A, 2007, 143: 1900-1905.

Lin J.S., Lew S.M., Marcuccilli C.J., Mueller W.M., Matthews A.E., Koop J.I. et al.: Corpus callosotomy in multistage epilepsy surgery in the pediatric population. J. Neurosurg. Pediatrics, 2011, 7: 189-200.

Luef G., Birbaumer G., Marosi M., Felber S., Kampfl A., Aichner F. et al.: Agenesis of the corpus callosum and epilepsy in two brothers. Neuropsychological and MRI features. Wien Klin Wochenschr., 1992, 104: 301-304.

Maeda M., Shiroyama T., Tsukahara H., Shimono T., Aoki S., Takeda K.: Transient splenial lesion of the corpus callosum associated with antiepileptic drugs: evaluation by diffusionweighted MR imaging. Eur. Radiol., 2003, 13: 1902-1906.

Maeda M., Tsukahara H., Terada H., Nakaji S., Nakamura
H., Oba H. et al.: Reversible splenial lesion with restricted diffusion in a wide spectrum of diseases and conditions. J. Neuroradiol., 2006, 33: 229-236.

Maehara T. and Shimizu H.: Surgical outcome of corpus callosotomy in patients with drop attacks. Epilepsia, 2001, 42: 67-71. Majkowska-Zwolinska B: Corpus callosum section as a surgical procedure in patients with drug resistant epilepsy. Epileptologia, 2002, 10: 17-49.

Makari G.S., Holmes G.L., Murro A.M., Smith, J.R., Flanagin, H.F., Cohen, M.J.: Corpus callosotomy for the treatment of intractable epilepsy in children. J. Epilepsy, 1989, 2: 1-7. McLeod N.A., Williams J.P., Machen B., Lum G.B.: Normal and abnormal morphology of the corpus callosum. Neurology, 1987, 37: 1240-1242.

Mirsattari S.M., Lee D.H., Jones M.W., Blume W.T.: Transient lesion in the splenium of the corpus callosum in an epileptic patient. Neurology, 2003, 60: 1838-1841.

Moreno-Jiménez S., San-Juan D., Lárraga-Gutiérez J.M., Celis M.A., Alonso-Vanegas M.A., Anschel D.J.: Diffusion tensor imaging in radiosurgical callosotomy. Seizure, 2012, 21: 473-477.

Mori K.: Giant interhemispheric cysts associated with agenesis of the corpus callosum. J. Neurosurg., 1992, 76: 224-230. Moutard M-L., Kieffer V., Feingold J., Kieffer F., Lewin F., Adamsbaum C. et al.: Agenesis of corpus callosum: prenatal diagnosis and prognosis. Childs Nerv. Syst., 2003, 19: 471-476. Narr K.L., Cannon T.D., Woods R.P., Thompson P.M., Kim S., Asunction D. et al.: Genetic contributions to altered callosal morphology in schizophrenia. J. Neurosci., 2002, 22:3720-3729. Nei M., O’Connor M., Liporace J., Sperling M.R.: Refractory generalized seizures: Response to corpus callosotomy and vagal stimulation. Epilepsia, 2006, 47: 115-122.

Ng Y-T., McCarthy C.M., Tarby T.J., Bodensteiner J.B.: Agenesis of the corpus callosum is associated with feeding difficulties. J. Child. Neurol., 2004, 19: 443-446.

Nielsen T., Montplaisir J., Lassonde M.: Sleep architecture in genesi of the corpus callosum: laboratory assessment of four cases. J. Sleep Res., 1992, 1: 197-200.

Nissenkorn A., Michelson M., Ben-Zeev B., Lerman-Sagie T.: Inborn errors of metabolism. A cause of abnormal brain development. Neurology, 2001, 56: 1265-1272.

Nosarti C., Rushe T.M., Woodruff P.W., Stewart A.L., Rifkin L., Murray R.M.: Corpus callosum size and very preterm birth: relationship to neuropsychological outcome. Brain, 2004, 127: 2080-2089.

O’Driscoll M.C., Jenny K., Saitta S., Dobyns W.B., Gripp K.W.: Agenesis of the corpus callosum and congenitallymphedema: A novel recognizable syndrome? Am. J. Med. Genet. A, 2010, 152: 1621-1626. 
Oguni H., Andermann F., Gotman J., Olivier A.: Effect of anterior callosotomy on bilaterally synchronous spike and wave and other EEG discharges. Epilepsia, 1994, 35: 505-513. Oguni H., Olivier A., Andermann F., Comair J.: Anterior callosotomy in the treatment of medically intractable epilepsies: A study of 43 patients with a mean follow-up of 39 months. Ann. Neurol., 1991, 30: 357-364.

Ono T., Baba H., Toda K., Ono K.: Callosotomy and subsequent surgery for children with refractory epilepsy. Epilepsy Res., 2011, 93: 185-191.

Pallini R., Aglioti S., Tassinari G., Berlucchi G., Colosimo C., Rossi G.F.: Callosotomy for intractable epilepsy from bihemispheric cortical dysplasias. Acta Neurochir., 1995, 132: 79-86. Paul L.K.: Developmental malformation of the corpus callosum: a review of typical callosal development and examples of developmental disorders with callosal involvement. J. Neurodevelop. Disord., 2011, 3: 3-27.

Paul L.K., Brown W.S., Adolphs R., Tyszka J.M., Richards L.J., Mukherjee P. et al.: Agenesis of the corpus callosum: genetic, developmental and functional aspects of connectivity. Nat. Rev. Neurosci., 2007, 8: 287-299.

Paul L.K., Van Lancker-Sidtis D., Schieffer B., Dietrich R., Brown W.S.: Communicative deficits in agenesis of the corpus callosum: nonliteral language and affective prosody. Brain Lang., 2003, 85: 313-324.

Pekala J.S., Mamourian A.C., Wishart H.A., Hickey W.F., Raque J.D.: Focal lesion in the splenium of the corpus callosum on FLAIR MR images: A common finding with aging after brain radiation therapy. Am. J. Neuroradiol., 2003, 24: 855-861.

Peltier J., Roussel M., Gerard Y., Lassonde M., Deramond H., Le Gars D. et al.: Functional consequences of a section of the anterior part of the body of the corpus callosum: evidence from an interhemispheric transcallosal approach. J. Neurol., 2012, 259: 1860-1867.

Phillips J. and Sakas D.E.: Anterior callosotomy for intractable epilepsy: outcome in a series of twenty patients. Br. J. Neurosurg., 1996, 10: 351-356.

Pinard J.M., Delalande O., Chiron C., Soufflet C., Plouin P., Kim Y. et al.: Callosotomy for epilepsy after West syndrome. Epilepsia, 1999, 40: 1727-1734.

Pisano T., Barkovich A.J., Leventer R.J., Squier W., Scheffer I.E., Parrini E. et al.: Peritrigonal and temporo-occipital heterotopias with corpus callosum and cerebellar dysgenesis. Neurology, 2012, 79: 1244-1251.

Piven J., Bailey J., Ranson B.J., Arndt S.: An MRI study of the corpus callosum in autism. Am. J. Psychiatry, 1997, 154: 1051-1056.

Plessen K.J., Grüner R., Lundervold A., Hirsch J.G., Xu D.,
Bansal R. et al.: Reduced white matter connectivity in the corpus callosum of children with Tourette syndrome. J. Child. Psychol. Psychiatry, 2006, 47: 1013-1022.

Polster T., Hoppe M., Ebner A.: Transient lesion in the splenium of the corpus callosum: three further cases in epileptic patients and pathophysiological hypothesis. J. Neurol. Neurosurg. Psychiatry, 2001, 70: 459-463.

Prilipko O., Delavelle J., Lazeyras F., Seeck M.: Reversible cytotoxic edema in the splenium of the corpus callosum related to antiepileptic treatment: Report of two cases and literature review. Epilepsia, 2005, 46: 1633-1636.

Provinciali L., Del Pesce M., Censori B., Quattrini A., Paggi A., Ortenzi A. et al.: Evolution of neuropsychological changes after partial callosotomy in intractable epilepsy. Epil. Res., 1990, 6: 55-165.

Quigley M., Cordes D., Turski P., Moritz C., Haughton V., Seth R. et al.: Role of the corpus callosum in functional connectivity. AJNR, 2003, 24: 208-212.

Rahimi S.Y., Park Y.D., Witcher M.R., Lee K.H., Marrufo M., Lee MR.: Corpus callosotomy for treatment of pediatric epilepsy in the modern era. Pediatr. Neurosurg., 2007, 43: 202-208. Rakic P. and Yakovlev P.I.: Development of the corpus callosum and cavum septi in man. J. Comp. Neurol., 1968, 132: 45-72.

Rappaport Z.H. and Lerman P.: Corpus callosotomy in the treatment of secondary generalized intractable epilepsy. Acta Neurochir., 1988, 94: 10-14.

Rash B.G. and Richards L.J.: A role for cingulated pioneering axons in the development of the corpus callosum. J. Comp. Neurol., 2001, 434: 147-157.

Rathore C., Abraham M., Rao R.M., George A., Sankara Sarma P., Radhakrishnan K.: Outcome after corpus callosotomy in children with injurious drop attacks and severe mental retardation. Brain Dev., 2007, 29: 577-585.

Raybaud C.: The corpus callosum, the other great forebrain commissures, and the septum pellucidum: anatomy, development, and malformation. Neuroradiology, 2010, 52: 447-477. Richards L.J., Plachez C., Ren T.: Mechanisms regulating the development of the corpus callosum and its agenesis in mouse and human. Clin. Genet., 2004, 66: 276-289.

Rossi A., Stratta P., D’Albenzi L.: Quantification of corpus callosum and ventricles in schizophrenia with nuclear magnetic resonance imaging: a pilot study. Am. J. Psychiatry, 1989, 146: 99-101.

Ryberg C., Rostrup E., Sjöstrand K., Paulson O.B., Barkhof F., Scheltens P. et al.: White matter changes contribute to corpus callosum atrophy in the elderly: The LADIS study. AJNR, 2008, 29: 1498-1504.

Saitoh O., Courchesne E., Egaas B., Lincoln A.J., Schreib- 
man L.: Cross-sectional area of the posterior hippocampus in autistic patients with cerebellar and corpus callosum abnormalities. Neurology, 1995, 45: 317-324.

Sakas D.E. and Phillips J.: Anterior callosotomy in the management of intractable seizures: Significance of the extent of resection. Acta Neurochir., 1996, 138: 700-707.

Sammler D., Kotz S.A., Eckstein K., Ott D.V., Friederici A.D.: Prosody meets syntax: the role of the corpus callosum. Brain, 2010, 133: 2643-2655.

Sass K.J., Novelly R.A., Spencer D.D., Spencer S.S.: $\underline{\text { Post- }}$ callosotomy language impairments in patients with crossed cerebral dominance. J. Neurosurg., 1990, 72: 85-90.

Sassower K.C., Rollison D.C., Duchowny M.: Outcome of corpus callosotomy and other pediatric epilepsy surgery: parental perceptions. Epil. Disord., 2001, 3: 197-202.

Schell-Apacik C.C., Wagner K., Bihler M., Ertl-Wagner B., Heinrich U., Klopocki E. et al.: Agenesis and dysgenesis of the corpus callosum: Clinical, genetic and neuroimaging findings in a series of 41 patients. Am. J. Med. Genet. A, 2008, 146: 2501-2511.

Sherr E.H., Owen R., Albertson D.G., Cotter P.D., Slavotinek A.M. et al.: Genomic microarray analysis identifies candidate loci in patients with corpus callosum anomalies. Neurology, 2005, 65: 1496-1498.

Shevell M.I.: Clinical and diagnostic profile of agenesis of the corpus callosum. J. Child. Neurol., 2002, 17: 895-899.

Shimojima K., Okumura A., Mori H., Abe S., Ikeno M., Shimizu T. et al.: De novo microdeletion of $5 q 14.3$ excluding MEF2C in a patient with infantile spasms, microcephaly, and agenesis of the corpus callosum. Am. J. Med. Genet. A, 2012, 158: 2272-2276.

Shu T. and Richards L.J.: Cortical axon guidance by the glial wedge during the development of the corpus callosum. J. Neusosci., 2001, 21: 2749-2758.

Silver J.: Glia-neuron interactions at the midline of the developing mammalian brain and spinal cord. Perspect. Dev. Neurobiol., 1993, 1: 227-236.

Sowell E.R., Mattson S.N., Thompson P.M., Jernigan T.L., Riley E.P., Toga A.W. et al.: Mapping callosal morphology and cognitive correlates. Effects of heavy prenatal alcohol exposure. Neurology, 2001, 57: 235-244.

Spencer S.S., Spencer D., Sass K., Westerveld M., Katz A., Mattson R.: Anterior, total, and two-stage corpus callosum section: Differential and incremental seizure responses. Epilepsia, 1993, 34: 561-567.

Spencer S.S., Spencer D., Williamson P., Mattson R.H.: Effects of corpus callosum section on secondary bilaterally synchronous interictal EEG discharges. Neurology, 1985, 35: 1689-1994.
Sreedharan S.E., Chellenton J., Kate M.P., Kesavadas C.: Reversible pancallosal signal changes in febrile encephalopathy: Report of 2 cases. AJNR, 2011, 32: 172-174.

Stancák A., Cohen E.R., Seidler R.D., Duong T.Q., Kim S.G.: The size of corpus callosum correlates with functional activation of medial motor cortical areas in bimanual and unimanual movements. Cereb Cortex, 2003, 13: 475-485. Stewart A.L., Rifkin L., Amess P.N., Kirkbride V., Townsend J.P., Miller D.H. et al.: Brain structure and neurocognitive and behavioural function in adolescents who were born very preterm. Lancet, 1999, 353: 1653-1657.

Suganthy J., Raghuram L., Antonisamy B., Vettivel S., Madhavi C., Koshi R.: Gender- and age-related differences in the morphology of the corpus callosum. Clin. Anatomy, 2003, 16: 396-403.

Sunaga S., Shimizu H., Sugano H.: Long-term follow-up of seizure outcomes after corpus callosotomy. Seizure, 2009, 18: 124-128.

Sztriha L., Al-Gazali L., Dawodu A., Bakir M., Chandran P.: Agyria-pachygyria and agenesis of the corpus callosum: Autosomal recessive inheritance with neonatal death. Neurology, 1998, 50: 1466-1469.

Tada H., Takanashi J., Barkovich A.J., Oba H., Maeda M., Tsukahara H. et al.: Clinically mild encephalitis/encephalopathy with a reversible splenial lesion. Neurology, 2004, 63: 1854-1858.

Tanriverdi T., Olivier A., Poulin N., Andermann F., Dubeau F. et al.: Long-term seizure outcome after callosotomy: a retrospective analysis of 95 patients. J. Neurosurg., 2009, 110: 332-342.

Taylor M. and David A.S.: Agenesis of the corpus callosum: a United Kingdom series of 56 cases. J. Neurol. Neurosurg. Psychiatry, 1998, 64: 131-134.

Teicher M.H., Dumont N.L., Ito Y., Vaituzis C., Giedd J.N., Andersen S.L.: Childhood neglect is associated with reduced corpus callosum area. Biol. Psychiatry, 2004, 56: 80-85.

Tomimoto H., Lin J-X., Matsuo A., Ihara M., Ohtani R., Shibata M. et al.: Different mechanisms of corpus callosum atrophy in Alzheimer's disease and vascular dementia. J. Neurol., 2004, 251: 398-406.

Van Wagenen W.P. and Herren R.Y.: Surgical division of commissural pathways in the corpus callosum: Relation to spread of an epileptic attack. Arch. Neurol. Psychiat., 1940, 44: 740-759.

Vossler D.G., Lee J.K., Ko T.S.: Treatment of seizures in subcortical laminar heterotopias with corpus callosotomy and lamotrigine. J. Child. Neurol., 1999, 14: 282-288.

Weinberg S.M., Parsons T.E., Fogel M.R., Walter C.P., Conrad A.L., Nopoulos P.: Corpus callosum shape is altered in 
individuals with nonsyndromic cleft lip and palate. Am. J. Med. Genet. A, 2013, 161: 1002-1007.

Witelson S.F.: The brain connection: the corpus callosum is larger in left-handers. Science, 1985, 229: 665-668.

Woodruff P.W.R., McManus I.C., David A.S.: Meta-analysis of corpus callosum size in schizophrenia. J. Neurol. Neurosurg. Psychiatry, 1995, 58: 457-461.

Yaguchi M., Yaguchi H., Itoh T., Okamoto K.: Encephalopathy with isolated reversible splenial lesion of the corpus callosum. Int. Med., 2005, 44: 1291-1294.

Yamauchi H., Fukuyama H., Nagahama Y., Katsumi Y., Hayashi T., Oyanagi C. et al.: Comparison of the pattern of atrophy of the corpus callosum in frontotemporal dementia, progressive supranuclear palsy, and Alzheimer's disease. J. Neurol. Neurosurg. Psychiatry, 2000, 69: 623-629.
Yamauchi H., Fukuyama H., Ogawa M., Ouchi Y., Kimura J.: Callosal atrophy in patients with lacunar infarction and extensive leukoaraiosis. An indicator of cognitive impairment. Stroke, 1994, 25: 1788-1793.

Yamauchi H., Fukuyama H., Ouchi Y., Nagahama Y., Kimura J., Asato R. et al.: Corpus callosum atrophy in amyotrophic lateral sclerosis. J. Neurol. Sci., 1995, 134: 189-196.

Yang T-F., Wong T-T., Kwan S-Y., Chang K.P., Lee Y.C., Hsu T.C.: Quality of life and life satisfaction in families after a child has undergone corpus callosotomy. Epilepsia, 1996, 37: 76-80.

Yonekawa T., Nakagawa E., Takeshita E., Inoue Y., Inagaki M., Kaga M. et al.: Effect of corpus callosotomy on attention deficit and behavioural problems in pediatric patients with intractable epilepsy. Epilepsy Behav., 2011, 22: 697-704. 